\title{
Effect of Table Tennis Trainings on Certain Physical and Physiological Parameters in Children Aged 10-12
}

\author{
Murat Taş ${ }^{1}$, Ahmet Sinanoğlu ${ }^{2}$ \\ ${ }^{1}$ Faculty of Sport Sciences, Manisa Celal Bayar University, Manisa, Turkey \\ ${ }^{2}$ Institute of Social Sciences, İbrahim Çeçen University, Ağrı, Turkey \\ Correspondence: Murat Taş, Faculty of Sport Sciences, Manisa Celal Bayar University, Halil Erdoğan Cd, Ahmet \\ Bedevi Mh, Manisa, Turkey.
}

Received: December 22, 2016

Accepted: January 6, 2017 Online Published: January 16, 2017

doi:10.11114/jets.v5i3.2095

URL: http://dx.doi.org/10.11114/jets.v5i3.2095

\begin{abstract}
In the research it was aimed to examine the effects of basic table tennis trainings, which were implemented on girls aged 10-12 for 16 weeks, on certain physical and physiological parameters.

A total of 40 students, as randomly selected 20 test groups and 20 control groups at an age range of 10-12 participated in the research. These students were first applied pre-test measurement, and final test measurement was performed following application of basic table tennis trainings for 16 weeks.

Statistical analysis of data was performed using SPSS 20.0 statistical package program. Mann Whitney U test was used in comparison of two variable groups, and the result being $\mathrm{p}<0.05$ was considered significant when examined statistically.

Statistical differences between measurements of body fat percentage, flexibility, vertical jumping, standing long jump, $30 \mathrm{~m}$ sprint, anaerobic strength, right and left hand grip strength, visual and audio reaction times, resting heart rate, and VC, FVC, FEV and FEV1 were found to be significant in favour of the test group $(p<0.05)$. No statistically significant differences occurred between the two groups in height, body weight, body-mass index, maxVo2, and systolic and diastolic blood pressure values $(\mathrm{p}<0.05)$.

Consequently, it was observed that the table tennis trainings, which were performed for 16 weeks, provided positive contributions to certain physical and physiological properties of girls aged 10-12, and improved them.
\end{abstract}

Keywords: child, table tennis, training, physical and physiological parameters

\section{Introduction}

It is easier at early ages to create the habit of sport and ingratiate sport; thus, foundations are laid of a generation doing sport and hence, of a healthier society (Çetin, 2015). Today, international successes achieved in sport have become a very significant value for the daily life and moral level of nation. As the records in sport are renewed with the aid of the science and technology, which advance every day, the technical, technological, training, educational, and economic standards of the country represented by the competing athletes or teams have become competitive (Polat, 2009). Table tennis improves concentration, reaction speed and coordination, arm and body muscles, and respiratory and circulatory functions; it also contributes to development of hand-eye coordination, timing and balance functions (Ağgön \& Ağırbaş, 2015). One of the effects of table tennis on humans is its effect on the body composition. Body composition in general is composed of proportional gathering of fat, bone, muscle cells, other organic substances and non-cellular fluids (Sanborn et al., 1994). It has been seen in various studies conducted that body composition develops positively with exercise activities (Çolakoğlu \& Şenel, 2003).

This study was conducted in order to examine the effect on certain physical and physiological parameters of table tennis trainings, which were applied 1 hour for 4 days a week for a period of 16 weeks on girls aged 10-12.

\section{Materials and Method}

40 (20 test, 20 control groups) girls selected randomly within the age range of 10-12 studying in Bitlis Tatvan Fatih Secondary School participated in the research. Basic table tennis trainings were applied 1 hour for 4 days a week for 16 
weeks on the test group, while no training was applied on the control group. Measurements in the research were performed by taking results of the pre-test as well as the final test at the end of 16 weeks.

\subsection{Tests Applied}

\subsubsection{Height and Body Weight Measurement}

Body weight of the subjects was measured barefoot in a height measuring scale with a sensitivity of up to 20 grams (Desis M301 brand). Their weights were again measured by adjusting the height test gauge on the scale such that it touched their heads (Zorba \& Ziyagil, 1995).

\subsubsection{Heart Rate}

Subjects were rested for 15 minutes before measuring heart rate. Heart rate was measured with the sphygmomanometer (Omron M2) attached to the left arms of the subjects (Günay et al. 2005).

\subsubsection{Systolic and Diastolic Pressure}

Subjects were rested for 15 minutes before measuring systolic and diastolic pressure. Systolic and diastolic pressure were measured with the sphygmomanometer (Omron M2) attached to the left arms of the subjects (Günay et al. 2005).

\subsubsection{Vertical Jumping}

A measurement stand was placed on the wall in a manner accessible by the subjects. Subjects tried to reach out to this measurement stand as much as they could with their feet contacting the ground, and later both the highest distance they could reach by jumping and this distance were measured. The difference between the height, which was reached by standing, and the height, which was reached by jumping, constituted the test result. Subjects were applied the test twice and their best grade was recorded (Kamar, 2003).

\subsubsection{Anaerobic Strength}

Anaerobic strength of the subjects was measured through the Sayers Formula ( $\mathrm{P}=60.7 \mathrm{Xvertical}$ jump distance+45.3XBody Weight) (Günay et al. 2005).

\subsubsection{0-meter Sprint}

Subjects ran at a speed of $30 \mathrm{~m}$ (standing) on a scaled ground with the start command, and the best of the two assessments was recorded (Hoare, 2000).

\subsubsection{Hand Grip Strength}

Right and left grip strengths of the subjects were measured with TTK digital hand dynamometer. Subjects were applied the test twice and their best grade was recorded (Günay et al. 2005).

\subsubsection{Body Mass Index}

Body mass index of the subjects was measured with Bodystat 1500 body analyser. Age, height and weight information were entered in the analyser while the subjects laid back. Measurements were taken from their right hand and right foot with the aid of an electro band.

\subsubsection{Body Fat Percentage}

Body fat percentage of the subjects was measured with Bodystat 1500 body analyser. Age, height and weight information were entered. Measurements were taken by adhering electro bands to the right hand and right foot of the subjects while they laid back.

\subsubsection{Standing Long Jump}

Start point was determined and starting line was drawn in order for the subjects to jump. Meter was opened next to the starting line in jumping direction of the subjects and adhered to the ground via bands. The distance they jumped as well as the distance between the jumping line and heel were measured. Best of the two assessments was recorded (Kamar, 2003).

\subsubsection{Flexibility}

Sit and reach test was used in measurement of flexibility. Test stand was $35 \mathrm{~cm}$ long, $45 \mathrm{~cm}$ wide and $32 \mathrm{~cm}$ high. Upper surface length of the stand was $45 \mathrm{~cm}$ and its width was $45 \mathrm{~cm}$. Upper surface was outside by $15 \mathrm{~cm}$ more than the surface its feet leaned on. $0-50 \mathrm{~cm}$ measurement grid was determined with parallel line intervals of $5 \mathrm{~cm}$ of each on the upper surface. Subjects sat on the ground and leaned their bare sole straight on the test stand. They slowly pushed the grid forward by bending their body forward and reaching forward as much as they could without bending their knees and keeping their hands in front of the body. They waited for 1-2 seconds at the furthest point without stretching forward or backwards. Test was repeated twice and the highest value was recorded (Günay et al. 2005). 


\subsubsection{Reaction Measurement}

Audio and visual reaction times of the subjects were detected using Newtest 1000 device. In measuring reaction times, attention was paid to the fact that measurement place was free of noise and received light. Two measurements were taken from each subject following a trial against light and sound warnings. Best value of the two measurements was recorded in milliseconds. Dominant hands of the subjects were used in measuring audio and visual reaction times (Tamer, 2000).

\subsubsection{Spirometric Measurements}

Respiratory measurements of the subjects were performed with Spirolab2 spirometer. Subjects were taken to test in rested condition. Vital capacity (VC), forced vital capacity (FVC), forced expiration volume in one second (FEV1), and forced expiration volume percentages in one second (FEV1\%) of the subjects were determined (Günay et al. 2005).

\subsubsection{MaxVO2 Measurement}

$20 \mathrm{~m}$. pull-up run test was applied for MaxVO2 measurement. $20 \mathrm{~m}$. pull-up run test cassette in compliance with the protocol was used in order to determine running speed. Subjects ran in a 20-meter track by touching the determined lines by their feet. The test was continued until the subjects made two errors. Test result was recorded as $\mathrm{ml} / \mathrm{kg} / \mathrm{min}$.

Fernhall formula $(0.35 \mathrm{X}$ (shuttle number)-0.59XVKI-4.61X (1) +50.6) was used in order to transform the total number of shuttle ran at the end of the shuttle run into maxvo2 value (Tamer, 2000).

\subsection{Table Tennis Training Program Applied}

Intensive interval training was used in our study, and training intensity was followed as 65\%. Fluid (water) intake was allowed according to individual requirement throughout the 16-week training period.

\begin{tabular}{lllll}
\hline Week & Work Hour & Work Place & Number of Student & Subject to be Handled \\
\hline 1. & $14.30-15.30$ & Table Tennis Hall & 20 & Introduction to Table and Paddle-free Moves with Ball \\
2. & $14.30-15.30$ & Table Tennis Hall & 20 & Paddle Holding and Dribbling with Paddle \\
3. & $14.30-15.30$ & Table Tennis Hall & 20 & Dribbling with Paddle \\
4. & $14.30-15.30$ & Table Tennis Hall & 20 & Paddle-free Forehand Serving at Table \\
5. & $14.30-15.30$ & Table Tennis Hall & 20 & Forehand Service Stroke with Paddle (Flat Service) \\
6. & $14.30-15.30$ & Table Tennis Hall & 20 & Backhand Service Stroke with Paddle (Reverse Service) \\
7. & $14.30-15.30$ & Table Tennis Hall & 20 & Forehand Drive (Flat Ball Strokes) \\
8. & $14.30-15.30$ & Table Tennis Hall & 20 & Forehand -Backhand Drive (Flat-Reverse Stroke) \\
9. & $14.30-15.30$ & Table Tennis Hall & 20 & Forehand -Backhand Drive (Flat-Reverse Stroke) \\
10. & $14.30-15.30$ & Table Tennis Hall & 20 & Smash.(Forehand and Backhand Stroke) \\
11. & $14.30-15.30$ & Table Tennis Hall & 20 & Chop. (Interrupted Strokes, Forehand) \\
12. & $14.30-15.30$ & Table Tennis Hall & 20 & Flip (Ball Stroke Workouts) \\
13. & $14.30-15.30$ & Table Tennis Hall & 20 & Drop (Short Ball Workouts) \\
14. & $14.30-15.30$ & Table Tennis Hall & 20 & Spin (Spin Strokes) \\
15. & $14.30-15.30$ & Table Tennis Hall & 20 & Spin (Spin Strokes) \\
16. & $14.30-15.30$ & Table Tennis Hall & 20 & Match Games
\end{tabular}

Figure 1. 16 Week Basic Table Tennis Training Program Applied (Asan, 2011).

Warn-up: 15 minutes Main training: 45 minutes Cool down: 5 minutes

\subsection{Data Analysis}

Statistical analysis of data was performed using SPSS 20.0 statistical package program in this study. Mann Whitney U test was used in comparison of two variable groups, and the result being $\mathrm{p}<0.05$ was considered significant when examined statistically.

\section{Findings}

When Table 1 is examined, no significant difference was observed between the participant test and control group children in initial and final measurements of their height, body weight and body mass index values $(\mathrm{P}>0.05)$. While no significant difference was observed between the test and control group in initial measurements of V.Y.Y. values $(\mathrm{P}>0.05)$, a significant difference was observed in favour of the test group in final measurement. 
Table 1. Comparison of the Physical Properties of Participants

\begin{tabular}{llllll}
\hline \multicolumn{1}{c}{ Variables } & & Test Group $\mathrm{n}=20$ & Control Group $\mathrm{n}=20$ & $\mathrm{Z}$ & $\mathrm{P}$ \\
\cline { 2 - 6 } & \multicolumn{1}{c}{ Height $(\mathrm{cm})$} & Pre Test $1.44 \pm 0.90$ & $1.39 \pm 0.97$ & -1.598 & .114 \\
& Post Test $1.46 \pm 0.92$ & $1.42 \pm 0.75$ & -1.329 & .192 \\
& Body Weight $(\mathrm{kg})$ & Pre Test $35.89 \pm 6.96$ & $33.27 \pm 4.97$ & -1.394 & .165 \\
& Post Test $35.53 \pm 6.74$ & $34.02 \pm 5.37$ & -.758 & .461 \\
V.Y.Y $(\%)$ & Pre Test $22.65 \pm 6.71$ & $24.97 \pm 5.75$ & -1.326 & .192 \\
& Post Test $21.23 \pm 5.84$ & $26.12 \pm 5.19$ & -2.394 & $.015^{*}$ \\
V.K.I $\left(\mathrm{kg} / \mathrm{m}^{2}\right)$ & Pre Test $16.87 \pm 3.03$ & $17.15 \pm 2.89$ & -.257 & .799 \\
& Post Test $16.63 \pm 2.94$ & $18.04 \pm 2.99$ & -1.191 & .242 \\
\hline
\end{tabular}

\section{$* \mathbf{p}<\mathbf{0 . 0 5}$}

Table 2. Comparison of Pre and Post Test Values of Participants

\begin{tabular}{llllll}
\hline Variables & & Test Group n=20 & Control Group n=20 & \multicolumn{1}{c}{$\mathrm{Z}$} & \multicolumn{1}{c}{$\mathrm{P}$} \\
\hline Flexibility (cm) & Pre Test & $16.70 \pm 4.90$ & $15.70 \pm 8.19$ & -.230 & .820 \\
& Post Test & $20.50 \pm 4.37$ & $14.75 \pm 7.53$ & -2.427 & $.014^{*}$ \\
Vertical Jumping (cm) & Pre Test & $13.85 \pm 4.88$ & $14.75 \pm 5.15$ & -.585 & .565 \\
& Post Test & $19.55 \pm 5.44$ & $12.35 \pm 4.57$ & -4.024 & $.000^{*}$ \\
Standing Long Jump (cm) & Pre Test $103.0 \pm 13.6$ & $96.55 \pm 18.7$ & -1.625 & .108 \\
& Post Test & $117.4 \pm 12.0$ & $92.60 \pm 18.4$ & -3.970 & $.000^{*}$ \\
30m (sec.) & Pre Test & $6.142 \pm .570$ & $6.417 \pm .670$ & -1.004 & .327 \\
\multirow{2}{*}{ Anaerobic Strength (W) } & Post Test $5.619 \pm .417$ & $6.477 \pm .554$ & -4.552 & $.000^{*}$ \\
& Pre Test $2466 \pm 371$ & $2402 \pm 363$ & -.189 & .862 \\
MaxVo2 (ml/kg/min.) & Post Test $2982 \pm 354$ & $2290 \pm 305$ & -4.815 & $.000^{*}$ \\
& Pre Test & $44.71 \pm 3.52$ & $44.51 \pm 2.49$ & -.027 & .989 \\
& Post Test $46.04 \pm 4.07$ & $44.06 \pm 3.55$ & -1.369 & .121 \\
\hline
\end{tabular}

$* \mathrm{p}<0.05$

When the above table is examined, no significant difference was observed between the two groups in the initial measurement in flexibility, vertical jump, standing long jump, $30 \mathrm{~m}$. sprint, and anaerobic strength values of the participant test and control group ( $\mathrm{P}>0.05$ ), while a significant difference in favour of the test group was observed in their final measurements (P>0.05). In Maxvo2 values, no significant difference was observed between the two groups in initial and final measurements.

Table 3. Comparison of Pre and Post Test Values of Participants

\begin{tabular}{llllll}
\hline \multicolumn{1}{c}{ Variables } & & Test Group n=20 & Control Group n=20 & Z & P \\
\hline Right Hand Grip Strength (kg) & Pre Test & $14.81 \pm 3.51$ & $13.23 \pm 3.35$ & -1.231 & .221 \\
& Post Test & $18.08 \pm 3.81$ & $13.02 \pm 3.02$ & -3.815 & $.000^{*}$ \\
Left Hand Grip Strength (kg) & Pre Test & $13.94 \pm 3.15$ & $11.73 \pm 3.93$ & -1.366 & .174 \\
& & & & \\
& Post Test & $18.47 \pm 3.82$ & $11.58 \pm 3.19$ & -4.844 & $.000^{*}$ \\
Visual Reaction (sec.) & Pre Test $.3050 \pm .076$ & $.3405 \pm .034$ & -1.724 & .086 \\
& Post Test $.2020 \pm .027$ & $.3695 \pm .063$ & -5.399 & $.000^{*}$ \\
Audio Reaction (sec.) & Pre Test $.3610 \pm .116$ & $.3750 \pm .047$ & -1.247 & .221 \\
& Post Test $.2135 \pm .034$ & $.3760 \pm .049$ & -5.436 & $.000^{*}$ \\
RHR (pulse/min.) & Pre Test $99.70 \pm 16.2$ & $101.0 \pm 8.47$ & -.542 & .602 \\
Blood Pressure Systolic (mm/Hg) & Post Test $87.40 \pm 9.61$ & $103.7 \pm 8.07$ & -4.321 & $.000^{*}$ \\
& Pre Test & $115.5 \pm 17.0$ & $112.5 \pm 14.0$ & -.252 & .820 \\
Blood Pressure Diastolic (mm/Hg) & Post Test $115.0 \pm 13.9$ & $122.5 \pm 11.1$ & -1.553 & .149 \\
& Pre Test $74.50 \pm 11.4$ & $71.00 \pm 20.2$ & -.098 & .925 \\
& Post Test $70.50 \pm 8.25$ & $75.00 \pm 9.45$ & -1.452 & .174 \\
\hline
\end{tabular}

$* \mathrm{p}<0.05$

According to the results in Table 3, while no significant difference was observed between the two groups in initial measurements of right and left hand grip strength, visual and audio reaction, and RHR (resting heart rate) values of the participant test and control groups $(\mathrm{P}>0.05)$, significant difference in favour of the test group was observed in their final 
measurements $(\mathrm{p}<0.05)$. In systolic and diastolic blood pressure values, no significant difference was observed between the two groups in initial and final measurements.

Table 4. Comparison of Pre and Post Test Values of Participants

\begin{tabular}{llllll}
\hline \multirow{2}{*}{ Variables } & & Test Group n=20 & Control Group n=20 & $\mathrm{Z}$ & $\mathrm{P}$ \\
\hline VC (lt) & Pre Test & $2.241 \pm .450$ & $1.981 \pm .365$ & -2.180 & $.028^{*}$ \\
& Post Test & $2.749 \pm .738$ & $1.957 \pm .301$ & -4.656 & $.000^{*}$ \\
FVC (lt) & Pre Test & $1.775 \pm .309$ & $1.740 \pm .280$ & -1.139 & .265 \\
& Post Test & $2.278 \pm .282$ & $1.716 \pm .267$ & -4.521 & $.000^{*}$ \\
FEV (lt) & Pre Test & $1.762 \pm .326$ & $1.777 \pm .264$ & -.163 & .883 \\
& Post Test & $2.296 \pm .260$ & $1.722 \pm .219$ & -4.985 & $.000^{*}$ \\
FEV1 (1t) & Pre Test & $90.55 \pm 4.18$ & $88.28 \pm 4.14$ & -1.773 & .076 \\
& Post Test & $92.78 \pm 4.69$ & $87.67 \pm 4.19$ & -3.274 & $.001^{*}$ \\
\hline
\end{tabular}

*p $<0.05$

When the above table is examined, significant differences in favour of the test group were found in initial and final measurements of the VC values of the participant test and control group children $(\mathrm{P}>0.05)$. While no significant differences were found between the two groups in initial measurements of FVC, FEV and FEV1 values $((\mathrm{P}>0.05)$, significant differences in favour of the test group formed in their final measurements $(\mathrm{P}>0.05)$.

\section{Discussion and Conclusion}

While no significant difference was observed in height, body weight, body mass index and body fat percentage values of the test and control group in their pre-study measurements, a significant difference in favour of the test group was observed in body fat percentage in their post-study measurements. Despite the fact that height increase arises from developmental properties, reduction in body weight, body fat percentage and body mass index of the test group can be associated with the trainings made.

When the studies related to height and body weight are examined; a total of 95 athletes at varying ages between 10-13, 52 boys and 43 girls participated in the research in which certain anthropometric properties and physical conformity parameters related to performance of the children dealing with athletics were evaluated. At the end of the research, it was found as $141.3 \pm 3.7 \mathrm{~cm}, 29.3 \pm 3.3 \mathrm{~kg}$ for 10 -year-old girls, and as $145.5 \pm 6.8 \mathrm{~cm}, 32,9 \pm 3,7 \mathrm{~kg}$ for 11-year-old, (Pekel et al. 2004).

In our study, body weights of the test group girls were found as $35.53 \pm 6.74 \mathrm{~kg}$, and their heights as $1.46 \pm 0.92 \mathrm{~cm}$.

In another research conducted, average height value of 78 female subjects aged 10 was found as $137.2 \pm 6.7 \mathrm{~cm}$, and as $139.7 \pm 8 \mathrm{~cm}$ in 11-year-old group girls (Çolak \& Kaya, 2006).

The values being in parallel is considered to be arise from the fact that the children are in developmental ages.

When the studies on the body mass index are examined; in the study they conducted on 177 children aged 12-14 in the province of Erzincan, Çolak \& Kaya (2006) calculated the body mass index average in 12-year-old group girls as $18.64 \pm 2.80 \mathrm{~kg} / \mathrm{m}^{2}$ for the provincial centre, while as $17.58 \pm 3.08 \mathrm{~kg} / \mathrm{m}^{2}$ for districts. While no significant difference was found as a result of the initial measurements between the test and control group, a significant difference in favour of the test group was found in the final measurement. Our research results showed parallelism with this research. In the study he performed, Kavak (2006) recorded the average body mass index of 78 female subjects aged 10 as $17.5 \pm 1.7 \mathrm{~kg} / \mathrm{m}^{2}$, of 97 female subjects aged 11 as $17.8 \pm 1.3 \mathrm{~kg} / \mathrm{m}^{2}$, and of 142 female subjects in 12 -year-old group as $18.2 \pm 1.2 \mathrm{~kg} / \mathrm{m}^{2}$.

In our study, final measurement values of the test group girls were found as $16.63 \pm 2.94 \mathrm{~kg} / \mathrm{m}^{2}$. Variation in values can be said to arise from the development of height and body weight.

While no significant difference was observed between the test and control group in initial measurements of V.Y.Y. values, a significant difference was observed in favour of the test group in final measurement.

Watts et al. (2003) have stated that mountaineers aged 11-12, who deal with various sports, have lower fat percentage than non-active children.

In another study performed, a significant reduction in terms of VYY was found in the test group compared to the control group as a result of the 10-week regular exercise (Şenel, 1995).

This can be regarded as the indicator that workouts performed reduce body fat percentage.

While no significant difference was found in the initial measurement between pre and post-study values of flexibility, vertical jump, standing long jump, $30 \mathrm{~m}$. sprint, anaerobic strength, and maxvo 2 of the test and control group, maxvo 2 value was not considered significant despite showing increase; significant differences in favour of the test group were found in all other values. 
When the studies on flexibility are examined; Pekel (2007) found in his study the flexibility value in 10-year-old group girls as $18.7 \pm 5.2 \mathrm{~cm}$. In the study conducted on 60 girls aged 9-10, average flexibility value was found as $20.84 \pm 3.88$ $\mathrm{cm}$, while the flexibility value of 60 girls aged 11 was found as $22.00 \pm 5.15 \mathrm{~cm}$ (Anindita et al. 2006). In our study the flexibility value of the female test group in the final measurement was found as $20.50 \pm 4.37 \mathrm{~cm}$. Data obtained in this study show parallelism with the above-mentioned study in terms of increase in flexibility values. Saygin has found significant differences in terms of flexibility between children with mild level of activity and children with medium level of activity (Saygin, 2003).

It can be said that the duration, severity and intensity of the workouts performed affect flexibility level.

When the studies on vertical jump are examined; in the study they performed on 776 girls aged 6-11, Turgut \& Çetinkaya (2006) found vertical jump average in girls as $29.25 \pm 5.66 \mathrm{~cm}$, while minimum value was determined as 16 $\mathrm{cm}$ and the maximum value as $48 \mathrm{~cm}$. While the average value in 11-year-old group girls (44) were found as $31.40 \pm 5.75$ $\mathrm{cm}$, the lowest value was specified as $21 \mathrm{~cm}$ and the highest value as $42 \mathrm{~cm}$. Katie et al. found differences in vertical jump values of the children receiving sport training compared to the children who do not receive sport training.

In our study the vertical jump distance of the test group children was found as $19.55 \pm 5.44 \mathrm{~cm}$. The fact that the increase in vertical jump distance, which is one of the explosive indicators between ages 10-12 in which physical development and performance development are continuous, is more in the test group can be associated with the effect of the workouts performed.

When the studies on standing long jump are examined; in the study they performed on 100 girls aged 10, Turgut \& Çetinkaya (2006) found the average standing long jump value as $123.81 \pm 20.15 \mathrm{~cm}$, while they found the minimum value as $85 \mathrm{~cm}$ and the maximum value as $184 \mathrm{~cm}$. In the study performed on 776 girls aged 6-11, the average standing long jump distance in the girls of the 10-year-old group (100 persons) was specified as $123.81 \pm 20.15 \mathrm{~cm}$.

Variability is seen between our finding $(117.4 \pm 12.0 \mathrm{~cm})$ and the findings of other researchers. This may be considered to arise from the fact that children are in developmental period as well as difference in sport ages and the contents of the trainings they do.

When the studies on $30 \mathrm{~m}$ sprint are examined; Loko et al. (2000) reported that 10-17-year-old children, who do exercise regularly, are faster than the children of their age and gender. Significant differences were found in 20, 30 and $40 \mathrm{~m}$ sprint values as a result of the exercise applied 3 days a week on children aged 10-12 (Diallo et al. 2001). Significant increase in $30 \mathrm{~m}$ sprint variable can be associated with the increases in strength parameters, increase of the anaerobic strength, and the workouts performed.

When the studies on anaerobic strength are examined, Medbo and Burgersn have reported that anaerobic strength can be increased by approximately 10\% through suitable 6-week training programs (Cicioğlu, 1995). Kien \& Chiodo (2003) have reported that 10-12-year-old secondary school children, who participate in recreational programs, are stronger than the children of their own age group, who do not participate in recreative sport activities.

It can be said that through the influence of the workouts performed, vertical jump and height increase values of the test group girls also increase the anaerobic strength and develop it more compared to the control group.

When the studies on MaxVO2 are examined, Rowland \& Boyajian (1995) found significant differences between the test group with an age average of 9 , who did aerobic exercise 30 minutes for 3 days a week, and the control group. In another study conducted, MaxVO2 development of children, who received regular and planned movement training, was found to be significant compared to active children in 11-12-year-old children (Themone et al., 2006). Erol et al. (1999) found significant development in terms of MaxVO2 in the test group compared to the control group as a result of 10-week regular exercise. In another study, significant differences were detected in MaxVO2 parameters as a result of the interval training, which was performed on 10-12-year-old children as 100-800 m and for 10 to 30 minutes with an intensity of 70-80\% (Mahen \& Voccaro 1999). The workouts performed can be said to have increased use of oxygen capacity in children.

While no significant differences occurred between the two group in initial measurements of pre and post-study of right and left hand grip strength, audio and video reaction times, and resting heart rates of the female test and control group, significant differences in favour of the test group occurred in the final measurements performed after the study. No significant difference occurred between the test and control group in initial and final measurements of systolic and diastolic blood pressure values.

When studies on right and left hand grip strength are examined; in the study performed by Anintida (2006), grip strength of 9-10-year-old group female subjects was found as $17.76 \mathrm{~kg}$, and of 11-year-old group as $22.17 \mathrm{~kg}$ in average. 
In our study the right hand grip strength was found as $18.08 \pm 3.81 \mathrm{~kg}$ and left hand grip strength as $18.47 \pm 3.82 \mathrm{~kg}$ in final measurements of the 10-12-year-old female test group. It is seen that the values obtained in this study are similar to the values obtained in the aforesaid study performed.

A feature of the tennis branch is the possibility to make strokes up to speeds of $200-2500 \mathrm{~km}$ with a strong grip and arm strength. Due to this feature, basic table tennis exercises are seen to improve grip strength. In this study it is considered that the children in the test group develop their hand grip strength positively.

When studies on visual and audio reaction times are examined, increase was found in terms of timing accuracy in children of the 7-10-year-old group receiving tennis training (Bengugui \& Ripoil, 1998). In the study he performed on children of 8-11-year-old group, Özer (2007) observed that mini tennis training reduced visual-audio reaction times of children by $21.21 \%$. In their study, Mouelhi et al. (2006) showed that the respond given to external environmental warnings can be accelerated through exercise.

16-week basic table tennis trainings displayed development in a positive way in reaction times of the test group girls. Table tennis is a sport branch which requires quick acceleration, rapid arm and whole body moves, and the ability to change direction quickly. It can the said that the 16 week trainings, which are based on scientific foundations and improve such properties, developed times of reaction against sound and light positively.

In a research conducted on resting heart rate, heart rate between ages 7-8 was determined as 90-92 pulses/min., as 96-108 pulse/min. between ages 9-10, and as 82-84 pulses/min. between ages 11-12. Children have higher minute volume compared to adults. Blood circulation process is shorter at these ages. Blood is delivered to the cells in child organism faster as a result of the physical movements performed (Coşan, 1992).

In our study final measurement values of the test group were found as $87.40 \pm 9.61 \mathrm{pulses} / \mathrm{min}$. It can be expressed that the values obtained in this study are similar to the values obtained in the aforesaid study performed.

The reason for reduction observed in resting heart rate values of the test group girls is considered to have developed depending on the increase in pulse volume which formed with the effect of training.

As a result of the study he performed, Pişkin (1998) determined systolic pressure value for 9-year-old group girls as $115.49 \mathrm{mmHg}, 112.74 \mathrm{mmHg}$ for 10 -year-old group girls, and diastolic pressure values for 9-year-old group as 77.14 $\mathrm{mmHg}$, as $75.08 \mathrm{mmHg}$ for 10 -year-old, and as $75.69 \mathrm{mmHg}$ for 11-year-old group.

In our study final measurement systolic pressure value of the 10-12 year of female test group was found as 115.0 \pm 13.9 $\mathrm{mmHg}$, diastolic pressure value as $70.50 \pm 8.25 \mathrm{mmHg}$.

When compared, results of our study and the literature results are partially similar.

Significant differences in favour of the test group were found in initial and final measurements of pre and post-VC values of the test and control group. While no significant differences were found between the two groups in initial measurements of FVC, FEV and FEV1 values, significant differences in favour of the test group formed in their final measurements.

Vijayan et al. (2000) conducted lung functional test in 469 children aged between 7 and 19. FVC and FEV 1 correlations were generally the highest regarding height, followed by weight and age. While height affected the equation substantially in boys, age and weight were more effective in girls. In the study, in which the effect of intensive swimming training on lung volume, airway resistance and maximal expiratory flow-volume in prepubertal girls, five girls, who did effective swimming training 12 hours a week, were compared to 11 girls from a control group attending various sport activities two hours a week. No significant difference was found in any of the parameters that were examined between the two groups prior to the training period. Following a one-year training, VC, total lung capacity and functional residual capacity were found to be higher in swimming girls than the control group (Courteix, 1997).

Aim of the study performed by Shephard \& Lavallee (1996) is to test the effect of enriched physical education program on static and dynamic lung volume growth and development of primary school children. 546 students aged 7-12 attended an additional 5 hours of physical education lesson every week. They found out that a regular physical education program can increase lung volume (FEV1, FVC) in primary school children. These findings show parallelism with the findings of our study.

The fact that vital capacity values displayed increase in favour of the test group children is considered to arise from the positive effect of training on respiratory system, while this increase in vital capacity is considered to have increased forced vital capacity as well as forced expiration volume in a second.

Consequently, development was observed in both the test and control groups due to the fact that the children were in developmental age; however, finding of the development in the test group to be higher than the control group was associated, along with the growth factor, with the basic table tennis trainings which were did for 16 weeks. 


\section{References}

Ağgön, E., \& Ağırbaş, Ö. (2015). Whe İnönü Üniversitesi, Journal of Physical Education and Sport Sciences, 2(2), $12-20$.

Anindita, M. (2006). Physical and motor fitness level of Indian school going girls. International Journal of Applied Sports Sciences, 18(2), 50-64.

Asan, R. (2011). Effect on eight-week table tennis exercise on attention in 9-13 year-old children. (Master's Thesis). Selçuk University, Konya, Turkey.

Bengugui, N., \& Ripoil, H. (1998). Effects of Tennis Practice on The Coincidence Timing Accuracy of Adults and Children. Research Quarterly for Exercise and Sport, 69(3), 217-223. https://doi.org/10.1080/02701367.1998.10607688

Çetin, H. N. (2015). Recommendations for Sport by Çetin, (Interview) http://www.milliyet.com.tr/sau-besyo-ogretim-uyesi-cetin-den-spor-sakaryayerelhaber-613899, (Access Date: 22.11.2016).

Cicioğlu, İ. (1995). Effect of polymetric training on vertical jump and certain physical and physiological parameters of 14-15-year-old group basketball players (Master's Thesis). Gazi University, Ankara, Turkey.

Çolak, M., \& Kaya, M. (2006). Evaluation of body mass index and skinfold parameters of 12-14-year-old children living in the province of Erzincan. Gazi University, Journal of Physical Education and Sport Sciences, 11(4), 23-30.

Çolakoğlu, F., \& Şenel, Ö. (2003). Effects of eight-week aerobic exercise program on the body composition and blood lipids of sedentary middle-aged women. Ankara University, Spormetre Journal, 13(1), 57-61.

Coşan, F., \& Demir, A. (1992). Physical conformity norms of Turkish children, Istanbul Olympic Games Preparation and Organization Committee Educational Publications, Issue No:1, Mart Matbaacılık, İstanbul, Turkey.

Courteix, D., Obert, P., Lecoqm A., Guenon, P., \& Koch, G. (1997). Effect of intensive swimming training on lung volumes, airway resistance and on the maximal expiratory flow-volume relationship in prepubertal girls. European Journal of Applied Physiology and Occupational Physiology, 76(3), 264-269. https://doi.org/10.1007/s004210050246

Diallo, O, Dore, E., Duche, P., \& Van Praagh, E. (2001). Effects of plyometric training followed by a reduced training programme on physical performance in prepubescent soccer players. Journal of Sports Medicine and Physical Fitness, 41(3), 342-8.

Erol, E., Cicioğlu, İ., \& Pulur, A. (1999). Effects of endurance training towards 13-14-Year-Old male basketball players on body composition and certain physical, physiological and blood parameters. Gazi University, Journal of Physical Education and Sport Sciences, 4, 12-20.

Günay, M., Tamer, K., \& Cicioğlu, İ. (2005). Sport physiology and performance measurement. Gazi Kitapevi, Ankara, Turkey.

Hoare, D. G. (2000). Predicting success in junior elite basketball players the contribution of anthropometric and physiological attributes. Journal of Science \& Medicine, 34, 391-405.

Kamar, A. (2003). Skill and performance tests in sport. Nobel Yayın Dağıtım, Ankara, Turkey

Katie, M. M., Brad, S. M., Joanne, K, Linda, D. V., \& Terence, J. W. (2003). Contribution of timetabled physical education to total physical activity in primary school children cross sectional study. Thebmj, 327, 592.

Kavak, V. (2006). The determination of subcutaneous body fat percentage by measuring skinfold thickness in teenagers in turkey. International Journal of Sport Nutrition and Exercise Metabolism, 296-304. https://doi.org/10.1123/ijsnem.16.3.296

Kien, C. L., \& Chiodo, A. R. (2003). Physical activity in middle school-aged children participating in a school-based recreation program. Archives of Paediatrics and Adolescent Medicine, 157(8), 811-815. https://doi.org/10.1001/archpedi.157.8.811

Loko, J, A. R., Sikkut, T., Ereline, J., \& Viru, A. (200). Motor performance status in 10 to 17-year-old Estonian girls and boys. Scandinavian Journal of Medicine and Science in Sports, 10(2), 109-113.

Mahen, A. D., \& Voccaro, P. (1999). Ventilatory threshold and vo2max changes in children following endurance training. Medicine and Science in Sport and Exercise, 21(4), 425-431. 
Mouelhi, G. S., Bouzaouach, I., Tenenbaum, G., Ben, K. A., Feki, Y., \& Bouaziz, M. (2006). Simple and choice reaction times under varying levels of physical load in high skilled fencers. Journal of Sports Medicine and Physical Fitness, 46(2), 344-351.

Özer, U. (2007). Effect of mini tennis training on development of coordination and reaction time in 8-11-year-old children (Master's Thesis). Cumhuriyet University, Sivas, Turkey.

Pekel, H. A. (2007). Normative study on certain variables in 10-12-year-old group children depending on seek of talent in athletics (Doctoral Thesis). Gazi University, Ankara, Turkey.

Pekel, H. A., Balcı, S. Ş., Pepe, H., Arslan, Ö., Bağcı, E., Tamer, K., \& Aydos, L. (2004). Evaluation of certain anthropometric properties and physical conformity parameters related to performance of children doing athletics. $8^{\text {th }}$ International Conference of Sport Sciences, Antalya.

Pişkin, B. (1998). Body measurements of 7-11-year-old-group children (Dissertation). Ondokuz Mayıs University, Samsun, Turkey.

Polat, G. (2009). Effects of 12-week basic badminton training exercises on motor functions and reaction times in 912-year-old-group children (Master's Thesis). Çukurova University, Adana, Turkey.

Rowland, T. W., \& Boyajian, A. (1995). Aerobic response to endurance exercise training in children. Paediatrics, 96(4), 654-8.

Sanborn, C. F., \& Janskowski, C. M. (1994). Physiologic considerations for women in sports. Clinics in Sport Medicine, 13(2), 315-325.

Saygin, Ö. (2003). Examination of physical activity levels and physical conformities of 10-12-year-old children (Doctoral Thesis). İstanbul, Turkey.

Şenel, Ö. (1995). Effects of aerobic and anaerobic trainings on certain physiological parameters of 13-16-year-old-group male students (Doctoral Thesis). Ankara, Turkey.

Shephard, R. J., \& Lavallee, H. (1996). Effects of enhanced physical education on lung volumes of primary school children. Journal of Sports Medicine and Physical Fitness, 36(3), 186-194.

Tamer, K. (2000). Measurement and evaluation of physical-physiological performance in sport. Bağırgan Yayımevi, Ankara, Turkey

Themone, M. J., Koppes, L. L. J., Kamper, H. C. G., Manyeki, K. D., \& Twisk J. W. R. (2006). The relationship between physical activity, fitness and educational achievement of rural South African children. Journal of Physical Education \& Recreation, 12(1), 32-38.

Turgut, A., \& Çetinkaya, V. (2006). Determination of certain motor functions in 6-11-year-old-group girls. $9^{\text {th }}$ International Conference of Sport Sciences, November 3-5, Muğla, Turkey.

Vijayan, V. K., Reetha, A. M., Kuppurao, K. V., Venkatesan, P., \& Thilakavathy, S. (2000). Pulmonary function in normal South Indian children aged 7 to 19 years. Indian Journal of Chest Disease and Allied Science, 42(3), 147-156.

Watts, P. B, Joubert, L. M., Lish, A. K., Mats, J. D., \& Wilkins, B. (2003). Anthropometry of young competitive sport rock climbers. British Journal of Sports Medicine, 37(5), 420-424. https://doi.org/10.1136/bjsm.37.5.420

Zorba, E., \& Ziyagil, M. A. (1995). Body composition and measurement methods. Gen Matbaacilık Reklamcilık Ltd. Şti., Ankara, Turkey.

\section{Copyrights}

Copyright for this article is retained by the author(s), with first publication rights granted to the journal.

This is an open-access article distributed under the terms and conditions of the Creative Commons Attribution license which permits unrestricted use, distribution, and reproduction in any medium, provided the original work is properly cited. 